\title{
Applying mindfulness to influence the patient and care team experience
}

\author{
Keerat S. Singh*1, Patricia Davis ${ }^{2}$, Mona Cockerham ${ }^{3}$ \\ ${ }^{1}$ Houston Methodist Willowbrook Hospital, Houston, United States \\ ${ }^{2}$ School of Nursing, University of Texas, Galveston, United States \\ ${ }^{3}$ Sam Houston State University, Huntsville, United States
}

Received: July 12, 2017

DOI: $10.5430 /$ jnep.v8n5p7
Accepted: September 3, $2017 \quad$ Online Published: December 17, 2017

URL: https://doi.org/10.5430/jnep.v8n5p7

\begin{abstract}
Objective: In today's work environment, specifically in health care, mindfulness is a personal and professional strategy to improve performance and productivity. To influence the patient and care team hospital experience through the concepts of mindfulness and perception.

Methods: This was a prospective observational project completed by medical/surgical nurses using an online survey pre- and post an educational program and an aggregate score of the 5 nurse-sensitive questions on the Hospital Consumer Assessment of Healthcare Providers and Systems (HCAHPS) survey, a survey based in the United States that is mailed to patients post discharge to home to measure patient satisfaction with their hospitalization. The HCAHPS survey is a patient satisfaction survey required by the Centers for Medicare and Medicaid Services (CMS) for all hospitals in the United States. The purpose of the HCAHPS survey is to provide a standardized survey instrument and data collection methodology for measuring patients' perspectives on their hospital care and hospital experience.

Results: The aggregate nurse-sensitive HCAHPS scores increased from 85.5 to 89.8 over one month. For mindfulness, after the educational program, among the ten nurse survey questions the percentage went up as much as $0.57 \%$.

Conclusions: An educational program related to the benefits of mindfulness can positively effect nurses' engagement in the workplace and positively increase HCAHPS scores. Continuing education on mindfulness should carry over month to month. In this research project, participants provided feedback to the researcher of feeling empowered to bring in new ideas, present different ways to grow, and tackle challenges.
\end{abstract}

Key Words: Hospital consumer assessment of healthcare providers and systems, Patient focused, Nonprofit, For-profit, Mindful, Health care

\section{INTRODUCTION}

Mindfulness is the capacity to intentionally bring awareness to present-moment experiences with an attitude of openness and curiosity. ${ }^{[1]}$ Through perceptions and mindfulness, patients attain a high level of expectations regarding the quality of health care services they should receive. This means that patients become more observant and more demanding for the standards of health care services they receive from the health care team. Patient care teams can learn emerging health care needs from patients and then structure their health care services in accordance with their patients' expectations. ${ }^{[2]}$ Mindfulness practices can enhance one's ability to pay attenStates.

*Correspondence: Keerat S. Singh; Email: kssingh2@houstonmethodist.org; Address: Houston Methodist Willowbrook Hospital, Houston, United 
tion and to notice what is actually happening; particularly in stressful situations. ${ }^{[1]}$ This ability to notice attentively and to see situations more clearly can help a person respond thoughtfully rather than react. This has particular relevance for nurses both in terms of self-care and in terms of optimal patient care. Perception and mindfulness can aid in changing HCAHPS scores, patient and care team experiences, and even the role of health care as a business in the real world. ${ }^{[2]}$ An institution's enforced quality initiatives ensure that the institution is focused not only on profit-making but also on the provision of high-quality services to the public, for example, a decrease in falls, skin breakdown, and catheter-associated urinary tract infections. ${ }^{[3]}$ Mindfulness is not something one can just do; it is a constant awareness that is learned and practiced. Being mindful is being aware of the present situation or circumstance. ${ }^{[4]}$

This project provided an intervention in the form of an inservice to educate staff on the "why" behind the institution's enforced quality initiatives. The goal was to increase the staff's mindfulness about patient-focused care to conclude if mindfulness increases both patient and staff satisfaction.

\subsection{Change theory}

Lewin's Change Theory identifies 3 stages through which change agents must proceed before change becomes part of a system: unfreezing, moving, and refreezing. Unfreezing takes place when change is needed, examining the status quo and increasing driving forces for change. Moving is when change is initiated and involves taking action, making changes, and involving people. Refreezing is when equilibrium is established, making the change permanent and establishing new processes. ${ }^{[5]}$ Lewin's Change Theory was used in this research project to explain the human processes expected to be observed through the changes in the HCAHPS scores of the subject staff and an increase in the health care team's mindfulness.

\subsection{Literature review}

The aspect of mindfulness is essential when handling patients in all health care facilities. This is because mindfulness enhances patient satisfaction with medical services. In recent times, the medical community has recognized the need to enhance the concept of mindfulness when dealing with patients. ${ }^{[6]}$ Numerous health care institutions today are evaluated according to how well they practice mindfulness when handling patients. ${ }^{[3]}$

The publication of Boey ${ }^{[2]}$ illustrated the close relationship that exists between the level of patient satisfaction in critical care and the nurses' perception and mindfulness of their working environment. A different publication authored by
Bush $^{[7]}$ suggests that numerous medical institutions in the United States today are taking a two-pronged approach to ensure that their HCAHPS scores are helpful rather than hurtful with regard to Medicare payments. In addition to working to improve competencies for the 18 core questions, such a two-pronged approach also addresses ways to improve the patient experience. The 18 core HCAHPS survey questions gauge the patients perception on how quickly their needs were met, if their needs were always met, communication amongst the healthcare team, discharge, pain, their overall hospital experience etc.

Donahue et al. ${ }^{[8]}$ suggest that there is a close connection between nurses' perceptions within the health care environment and the level of patient satisfaction. In addition, according to Fabry, ${ }^{[9]}$ both perceptions and perspectives when handling patients must be implemented by the nursing staff to attain patient satisfaction. This phenomenon was also supported by Frampton and Charmel, who emphasized the need for nurses to put patients' needs first in patient-centered care as a way of maximizing the patient's level of satisfaction. ${ }^{[10]}$

Ronald Epstein, a medical psychologist and professor at University of Rochester School of Medicine, studied mindfulness in health care practices in 1999. Epstein concluded that mindful practitioners attend in a nonjudgmental way to their own physical and mental processes during ordinary, everyday tasks. This critical self-reflection enables health care providers to listen attentively to patients' distress, recognize errors, make evidence-based decisions, and clarify their values so that they can act, treat, and care with compassion, competence, presence, and insight. ${ }^{[4]}$

\section{Methodology}

\subsection{Setting}

This project was conducted in a community hospital. The project took place on a stroke/neurology and medical/surgical floor of a 313-bed acute care hospital from September to October 2016.

\subsection{Timeline and sampling procedure}

The subject staff was notified of an upcoming study via fliers posted on the hospital nursing units, unit meetings, shift change huddles, and reminder emails. Additionally, in September 2016 a "Did You Know" poster board was created and posted on the unit for the staff to view and reference. The educational program emphasized evidence-based practice, non-profit versus profit organization, value-based purchasing (VBP), HCAHPS survey, patient centered care: what does it take, and hospital reimbursement in regards to CMS guidelines. VBP are individual measures that are assigned one of several domains; including process, outcomes, and 
patient experience and efficiency. Each of these domains has a percentage weight used to calculate the hospitals total performance score. VBP and HCHAPS scores are used to determine a hospital's reimbursement. Additionally, during the in-service, the attendees completed an activity before the start of the presentation that included nurse-sensitive HCAHPS survey questions. Two weeks after the intervention, the nurses completed post-intervention surveys containing the same 10 questions as in the pre-intervention survey to assess whether their mindfulness had increased.

HCAHPS is a standardized, national, publicly reported survey sent to all patients who are discharged home. The survey compiles the scores of the responses received from the discharged patients' of their perspectives on the nature of care offered to them in hospitals. Consequently, the HCAHPS score provides an objective as well as a meaningful comparison of different hospitals and how staff interacts with patients. To avoid a low ranking on the HCAHPS scores, health care institutions are forced to raise their standards concerning patients' health. Accordingly, the HCAHPS surveys act as an incentive for medical facilities to improve the quality of their patient care services. Furthermore, the public reporting through the HCAHPS surveys enhances accountability in health care facilities. Consequently, this enhances trans- parency in the quality of hospital care offered in return for the attained public investment. ${ }^{[5]}$ The HCAHPS survey is a patient satisfaction survey required by CMS for all hospitals in the United States.

\subsection{Instruments/tools}

Singh created a pilot survey consisting of 10 survey questions specific to understanding mindfulness in this group of nurses. The participating nurses completed the same survey before and after the in-service presentation. All questions except question number two had 5 choices; question number two had 2 choices. Each response was weighted from 1 to 5 , with 5 being the most desirable response and 1 being the least desirable. For question number two, which had only 2 choices, a weight of 5 was given to responses that agreed and a weight of 4 was given to responses that did not agree.

This survey was not tested for validity but was used as a baseline to understand the nurse's perception of mindfulness. Pre-intervention surveys were given to the staff to gauge their current perceptions and thoughts about patientfocused care in today's health care environment. The survey examined staff members' feelings and perceptions about patient-focused care, both before and after the in-services were completed (see Table 1). An anonymous, online survey method was used via surveymonkey.com.

Table 1. Scores on the mindfulness survey given to nurses on a stroke/neurology and medical/surgical floor before and after an in-service intervention

\begin{tabular}{|c|c|c|c|}
\hline Question & Pre-Intervention Survey Results* & Post-Intervention Survey Results* & Difference \\
\hline $\begin{array}{l}\text { Please indicate your feelings about } \\
\text { patient centered care in today's } \\
\text { healthcare world. }\end{array}$ & 3.86 & 4.23 & 0.37 \\
\hline $\begin{array}{l}\text { Please indicate your thoughts on } \\
\text { nursing as a business. }\end{array}$ & 4.66 & 4.81 & 0.15 \\
\hline I understand what HCAHPS survey is. & 4.33 & 4.67 & 0.34 \\
\hline $\begin{array}{l}\text { I understand why the HCAHPS survey } \\
\text { is patient focused. }\end{array}$ & 4.16 & 4.73 & 0.57 \\
\hline $\begin{array}{l}\text { I understand why we do what we are } \\
\text { doing for our patients? (i.e.: hospital } \\
\text { quality initiatives: hourly rounding, } \\
\text { pain management, etc.) }\end{array}$ & 4.54 & 4.87 & 0.33 \\
\hline $\begin{array}{l}\text { How satisfied are you with your job as } \\
\text { a nurse? }\end{array}$ & 3.77 & 4.13 & 0.36 \\
\hline Are you burnt out? & 2.65 & 2.73 & 0.08 \\
\hline $\begin{array}{l}\text { Do you regularly “commit to sit” with } \\
\text { your patient? }\end{array}$ & 4.21 & 4.65 & 0.44 \\
\hline $\begin{array}{l}\text { Do you regularly listen to your } \\
\text { patient’s needs and concerns? }\end{array}$ & 4.81 & 4.87 & 0.06 \\
\hline $\begin{array}{l}\text { Do you explain things to your patients } \\
\text { including their plan of care? }\end{array}$ & 4.40 & 4.52 & 0.12 \\
\hline
\end{tabular}


The following activity was given to participants who attended an in-service. The activity was given at the start of the inservice and was discussed with the participants after the in-service and was a "take away" for the participants. The questions that are non-italicized are questions from the actual HCAHPS survey patients receive upon discharge. The italicized questions are questions that were asked as a part of the project to gauge the thoughts of the subject staff if they or a loved one were a patient in a hospital setting. The idea was to increase mindfulness and increase the unit's HCAHPS scores. Both non-italicized and italicized questions were part of the "take away".

(1) During this hospital stay, how often did nurses treat you with courtesy and respect? How would you define courtesy and respect? What would your expectations be?

(2) During this hospital stay, how often did nurses listen carefully to you? Would you want your nurses to actually listen to you, and listen carefully? How often?

(3) During this hospital stay, how often did nurses explain things in a way you could understand? How important is it to you for nurses to explain things to you or your family member; such as plan of care and in a way you and/or your family member can understand?

(4) During this hospital stay, after you pressed the call button, how often did you get the help as soon as you wanted it? If you or a family member pressed the call button; would your expectation be for a response to your needs in a timely manner? What is considered a timely manner to you?

(5) How often did you get help in getting to the bathroom or in using a bedpan as soon as you wanted? If you or your family member needed help getting to the bathroom or using a bedpan; how much time is an acceptable amount of time to wait for help?

(6) During this hospital stay, how often did the hospital staff do everything they could to help you with your pain? How often would you expect your pain to be controlled as a patient? What would you do if the pain wasn't being controlled?

(7) Before giving you any new medicine, how often did the hospital staff tell you what the medicine was for? How often did the hospital staff describe possible side effects in a way you could understand? Would you want to be notified for every new medicine prescribed to you during your hospital stay? Know why it was prescribed? What the side effects were? If you weren't notified; what would you think? How would you feel?

As a baseline, data were collected on HCAHPS scores by patient discharge date for September 2016. Nurses completed the pre-survey questionnaire about their knowledge and perception of mindfulness. Next, they received an educational presentation on mindfulness titled: Mindfulness: Influencing the Patient and Care Team Experience. Following the educational program, the nurses completed a post-survey to measure a change in their understanding and knowledge of mindfulness.

The educational program was a 1-hour educational program PowerPoint (Microsoft Corp, Redmond, WA). The primary researcher of this study provided the educational presentation. The program encourages nurses to "Nurse out Loud," which is to explain verbally "out loud" to the patient the tasks they are e doing to provide patient care and why to the patient. For example: "I am flushing your IV for your safety, I am emptying your urinal for your comfort, and I am closing the curtain for your privacy." The italicized words used in the examples above are key words that are part of a quality initiative implemented at the hospital.

\subsection{Sampling subjects and size}

The staff included a unit manager, a night administrative coordinator, charge nurses, registered nurses, patient care assistants, and unit secretaries for both day and night shift. At the time of this research project, the subject staff numbered 70 persons. Of the 70 staff members, 43 took the preintervention survey (61\% of staff), 39 attended an in-service (55\% of staff), and 31 took the post-intervention survey (45\% of staff). A total of 43 nurses participated in the project. To determine if mindfulness had increased, scores on the preand post surveys were compared for each individual question. Also, HCAHPS scores for September and October were compared to determine if mindfulness educational program would increase the unit's HCAHPS scores. An anonymous survey method was used for the subject staff to complete both pre- and post surveys using surverymonkey.com. At the completion of the survey, surveymonkey.com calculated the percentages noted above.

\section{RESULTS}

The nurses' response scores on the mindfulness survey and the aggregate nurse-sensitive HCAHPS score increased from 85.5 to 89.8 over one month on HCAHPS; an increase of $4.3 \%$. For mindfulness, after the educational program, among the ten nurse survey questions the percentage went up as much as $0.57 \%$. We found an increase in the knowledge of mindfulness following the educational program using a pre-post survey methodology. An aggregate score of the 5 nurse-sensitive questions on the HCAHPS survey were used for the purpose of this study.

The differences in the pre- and post-intervention survey 
scores are reported in Table 1. As shown by scores on the ness of patient-focused care. The changes in survey scores survey, the staff showed noticeable improvement in mindful- are presented visually in Figure 1.

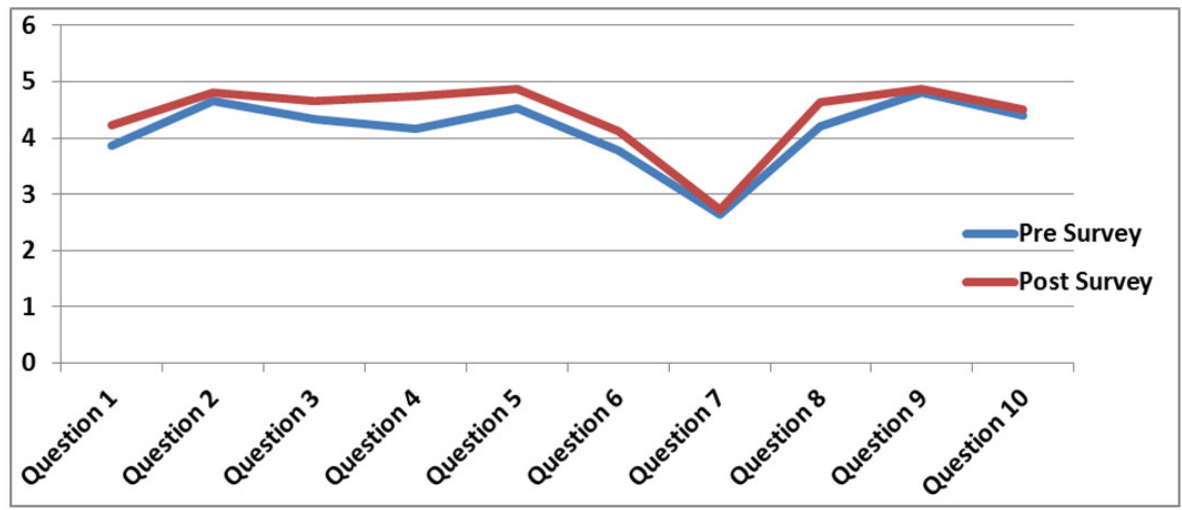

Figure 1. This graph shows changes in mindfulness as shown by improvement in scores from before (pre-survey) to after (post-survey) the educational intervention

\section{DISCUSSION AND BARRIERS}

The research aim of this project was to influence the patient and care team experience through the education on the concepts of mindfulness. In today's work environment, specifically in health care, mindfulness is a personal and professional strategy for improving performance, communication, and productivity. According the post intervention assessment the mindfulness of the nurses in the first month after the intervention may have improved nurse-sensitive patient satisfaction scores in areas for the five questions evaluated: focus and clarity, listening, and decision-making skills and overall patient happiness and well-being. The literature reports that mindfulness can reduce employee absenteeism and turnover, improve employee and client relationships, and boost job satisfaction. ${ }^{[6]}$

\section{Strengths and limitations}

A strength of this project was the education program: "Nurse Out Loud" which educated nurses on the value of mindful- ness and HCAHPS scores increase following this education. Limitations included complications with collecting demographic information of the subject staff, use of a pilot instrument to measure mindfulness, and basic statistical measures of central tendency. Lastly, there was a short interval of assessment after the educational intervention. The results may have been different if the post-education assessment had taken place after a longer time, or if reinforcing education had been revisited in staff meetings monthly.

\section{ACKNOWLEDGEMENTS}

I thank Dr. Patricia Davis of the Graduate School of Nursing at the University of Texas Medical Branch and my Capstone Project committee members: Debra Trometer, Dana Scott, and Dr. Mona Cockerham. I also thank the unit manager, LaTasha Broussard, and the staff who participated in the surveys.

\section{CONFlicts of InTEREST Disclosure}

The authors declare that there is no conflict of interest.

\section{REFERENCES}

[1] Morgan P, Simpson J, Smith A. Health care workers' experiences of mindfulness training: a qualitative review. Mindfulness. 2015; 6(4): 744-758. https://doi.org/10.1007/s12671-014-0313-3

[2] Boev $\mathrm{C}$. The relationship between nurses' perception of work environment and patient satisfaction in adult critical care. J Nurs Scholarsh. 2012; 44(4): 368-375. https://doi .org/10.1111/j.1547-506 $9.2012 .01466 . \mathrm{x}$

[3] NDNQI (National Database of Nursing Quality Indicators) 2016. Available from: http://www.pressganey.com/solutions/cli nical-quality/nursing-quality

Published by Sciedu Press
[4] Epstein, Ronald. How Mindfulness Can Lead to Better Health Care Outcomes. University of Pennsylvania-Wharton. 2017. "Mindful Practice." University of Rochester School of Medicine, Rochester, New York: 1999

[5] Stanowski AC, Simpson K, White A, et al. Pay for performance: are hospitals becoming more efficient in improving their patient experience? J Healthc Manag. 2015; 60(4): 268. PMid:26364350 https://doi.org/10.1097/00115514-201507000-00008

[6] Horner J, Piercy B, Eure L, et al. A pilot study to evaluate mindfulness as a strategy to improve inpatient nurse and patient experiences. Appl Nurs Res. 2014; 27(3): 198-201. https://doi.org/10.101 
6/j.apnr.2014.01.003

[7] Bush H. Doubling down on the patient experience: many hospitals are taking a two-pronged approach to make sure HCAHPS scores help, rather than hurt, Medicare payments. Hospitals \& Health Networks [Internet]. 2011 Dec; 85(12): 22. Available from: http://www.hhnmag.com/articles/4353-doubling-d own-on-the-patient-experience PMid:22295587

[8] Donahue MO, Piazza IM, Griffin MQ, et al. The relationship between nurses' perceptions of empowerment and patient satisfaction. Appl
Nurs Res. 2008; 21(1): 2-7. https ://doi.org/10.1016/j.apnr .2007 .11 .001

[9] Fabry D. Hourly rounding: perspectives and perceptions of the frontline nursing staff. J Nurs Manag. 2015; 23(2): 200-210. https: //doi.org/10.1111/jonm.12114

[10] Frampton SB, Charmel PA. Putting patients first: best practices in patient-centered care. 2nd ed. San Francisco (CA): Jossey-Bass; 2009. 